\title{
Is Smaller Better? A Comment on "Comparative Economic Impact Analyses” by Michael Mondello and Patrick Rishe
}

\author{
Victor A. Matheson
}

November 2004

\section{COLLEGE OF THE HOLY CROSS, DEPARTMENT OF ECONOMICS \\ FACULTY RESEARCH SERIES, WORKING PAPER NO. 04-07*}

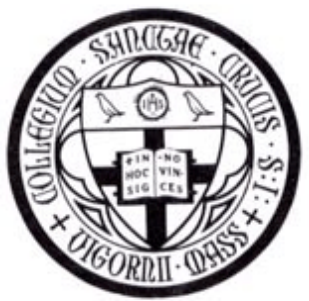

Department of Economics

College of the Holy Cross

Box 45A

Worcester, Massachusetts 01610

(508) 793-3362 (phone)

(508) 793-3710 (fax)

http://www.holycross.edu/departments/economics/website

*All papers in the Holy Cross Working Paper Series should be considered draft versions subject to future revision. Comments and suggestions are welcome. 


\title{
Is Smaller Better? A Comment on "Comparative Economic Impact Analyses” by Michael Mondello and Patrick Rishe
}

\author{
Victor A. Matheson ${ }^{\dagger}$ \\ College of the Holy Cross
}

November 2004

\begin{abstract}
In a recent article in Economic Development Quarterly, “Comparative Economic Impact Analyses: Differences Across Cities, Events, and Demographics” (November 2004), Michael Mondello and Patrick Rishe examined the economic impact of small, amateur sporting events on host economies. This response to their work suggests four reasons why ex ante economic impact estimates for smaller sporting events may come closer to matching ex post reality than those for "mega-events" including less crowding out, lower hosting costs, higher multipliers, and less incentive for boosters to published inflated figures.
\end{abstract}

JEL Classification Codes: L83 - Sports; Gambling; Recreation; Tourism

Keywords: economic impact, sports, sport economics

${ }^{\dagger}$ Victor A. Matheson, Department of Economics, Box 157A, College of the Holy Cross, Worcester, MA 01610-2395, 508-793-2649 (phone), 508-793-3710 (fax), vmatheso@holycross.edu 
“Is Smaller Better? A Comment on ‘Comparative Economic Impact Analyses’ by Michael Mondello and Patrick Rishe”

\section{INTRODUCTION}

In a recent article in Economic Development Quarterly, “Comparative Economic Impact Analyses: Differences Across Cities, Events, and Demographics” (November 2004), Michael Mondello and Patrick Rishe examined the economic impact of sporting events. Their scholarly work is distinguished by its focus on smaller amateur events such as the NCAA Women's Final Four basketball tournament, the NCAA Division I wrestling championships, and the national Junior and Senior Olympic games. Most previously published studies of sporting events have tended to focus on huge “mega-events” such as the Super Bowl (Porter, 1999; Baade and Matheson, 2000b), the World Cup (Baade and Matheson, 2004a), large auto races such as the Daytona 500 (Baade and Matheson, 2000a) or Indy 500 (Rosentraub, 2000), the Olympics (Kasimati, 2003), or post-season play in the "big four” professional sports (Coates and Humphreys, 2002). Independent studies of mega-events routinely conclude that ex ante estimates of the economic benefits of these events overestimate the actual ex post benefits by a wide margin. A common rule of thumb used by experts in the field simply reduces published advocacy estimates by a factor of ten in order to get a more accurate assessment of the true impact of an event on the host community.

While all of the events examined by Mondello and Rishe are studied using ex ante analysis, they make a convincing case that their ex ante predictions will provide a reasonably accurate estimate of the true effect of these events on the local economies. This result begs the 
question of why ex ante estimates of small events are so much more accurate than ex ante estimates of mega-events. This short comment provides four possible explanations for this finding, gives recommendations for local development authorities, and provides directions for future research.

\section{COMPARING SMALLER EVENTS TO MEGA-EVENTS}

\section{Crowding Out}

A primary flaw that economists find with many economic impact studies is that little consideration is taken for the fact that event visitors may displace ordinary tourists and business travelers who wish to avoid the crowds and congestion associated with a mega-event. The Super Bowl, for example, takes place annually in January, usually in warm, tourist-friendly cities. Hotels in these cities generally experience relatively high occupancy rates during the Super Bowl weekend even in the years in which they do not host the championship game. Similarly, Daytona Beach is a popular winter destination and would attract significant numbers of tourists in February even without the Daytona 500. The fundamental shortcomings of these studies involves the failure to identify changes in spending by residents of the host community and a "netting out" of spending reductions by those who would have visited the host city, but are "crowded out” by sports fans.

Crowding out is much less likely to occur during a small event than during a mega-event. It is difficult to believe that large numbers of travelers will fundamentally change their travel plans due to a relatively minor occasion such as a local marathon or amateur track and field competition, and therefore these events may get all of the benefits of increased visitor spending 
without the costs of displaced visitors.

\section{Costs of Hosting and Security}

The high profile of mega-events makes hosting them extraordinarily expensive, especially in the wake of 9/11. Unfortunately, mega-events present prime targets for terrorists as witnessed by the bombing of the 2000 Olympic Games in Atlanta and the Israeli athlete tragedy at the 1972 Munich games. In response to terrorist threats, Greece spent approximately \$1.3 billion for security alone for the 2004 Summer Games. Along similar lines, the security measures put in place for the 2004 Democratic and Republican National Conventions in Boston and New York City required closing down significant portions of these cities' transportation networks and resulted in major disruptions in the lives of the cities’ citizens. These disruptions (along with crowding out) translated into decreased economic activity in the host cities despite the presence of tens of thousands of conventioneers and media personnel. For example, attendance at Broadway shows during the Republican National Convention in New York City in 2004 was $18 \%$ lower than the same period a year earlier.

While security measures cannot be ignored for minor sporting events (who would have imagined prior to April 19, 1995 that Oklahoma City would be a prime terrorist target), the security costs and the local inconveniences caused by toughened security measures will be orders of magnitude lower than for mega-events.

In addition, higher profile events also place additional demands on local organizers. While amateur competitions must content themselves with available facilities, mega-events generally demand very costly state-of-the-art facilities and first-class accommodations for 
athletes as a condition for hosting the event. Of course, event boosters justify these additional costs by claiming high returns. Even if mega-events do result in large economic benefits, an obviously contentious claim in and of itself, the high costs of hosting certainly reduce net benefits organizers and local governments. For example, after costs were accounted for, the Texas Comptroller estimated the net benefits to the state from Super Bowl XXXVIII held in Houston in January 2004 were less than $\$ 1$ million.

On a more mundane line, mega-events simply require larger (and consequently more expensive) sporting facilities that are likely to be little used in future. Few cities have a need for natatorium seating 10,000 spectators as would be required to host the Olympics. Smaller swimming facilities, however, could frequently be used for events such as high school or collegiate championships while still accommodating most anticipated crowds. Quite simply put, mega-events cause over-investment in rarely used sports facilities.

\section{Multiplier Analysis}

Ex ante economic impact analysis is generally done by estimating direct spending at an event, and then applying a multiplier to account for money circulating through the economy after the initial round of spending. The economic multipliers used in these analyses are calculated using complex input-output tables for specific industries based upon inter-industry relationships within regions based upon an economic area’s normal production patterns. During mega-events, however, the economy within a region may be anything but normal, and therefore, these same inter-industry relationships may not hold. Since there is no reason to believe that the usual economic multipliers are the same during mega-events, any economic analyses based upon these 
multipliers may, therefore, be highly inaccurate.

For example, nationally-owned hotel chains commonly raise their regular room rates during mega-events (by up to a factor of four), the presence of a mega-event results in abnormal windfall profits to the hospitality industry much of which will immediately leave the host city. Wages paid to local workers, money that typically stays and recirculates in the host city, however, are unlikely to change significantly. Since the proportion of income earned by a city's businesses and workers that leaves the city increases during mega-events, any multipliers based on typical business patterns will be artificially high when applied to mega-events (Matheson, 2004).

Since smaller events are less likely to cause deviations from normal business patterns, the multipliers applied for these events are much more likely to represent an accurate estimate of indirect spending.

\section{Political Economy}

A final reason that economic impact estimates from small events may come closer to reality than those of mega-events is that smaller events may have less incentive to produce inflated results. Sports leagues routinely use All-Star games and league championships as a carrot to entice otherwise reluctant cities into providing large subsidies for new sports infrastructure. Of the 15 Major League Baseball stadiums built between 1970 and 1997, 13 were selected to host an All-Star Game within 5 years of construction (Baade and Matheson, 2001). Similarly, immediately prior to a recent vote in Arlington, Texas that would provide public funding for a new stadium for football’s Dallas Cowboys, National Football League 
Commissioner Paul Tagliabue promised the city a future Super Bowl if the new stadium was built and touted the large economic benefits of the big game on the local economy. Obviously, if the lure of a mega-event is being used to convince skeptical taxpayers to spend public funds for stadium construction, the league has every incentive to inflate the benefits of the mega-events as much as possible. Furthermore, since mega-events inconvenience local citizens due to crowds, congestion, and increased security measures, local politicians want to point to large economic gains for the city to assuage public skepticism regarding these events.

Smaller events are much less frequently used to justify public expenditures on infrastructure, and they less often ask for handouts to defray hosting costs. Therefore, these competitions have significantly less incentive to artificially inflate their economic impact figures.

\section{CONCLUSIONS AND RECOMMENDATIONS}

Mondello and Rishe's work clearly suggests a prime area for future economic research: the study of ex post economic gains from less prominent sporting events. While the highly publicized claims of huge economic benefits from mega-events have been widely debunked by a number of ex post academic studies, the field of amateur events is nearly untouched. (See Baade and Matheson (2004b) for one such ex post study of the NCCA Men's and Women's basketball tournaments.) It must be noted that isolating the effects of a sporting contest in a large, diverse metropolitan economy is demanding even with mega-events and will be comparatively harder as the size of the event diminishes. This difficulty, however, is tempered by the fact that smaller events often take place in small and medium-sized cities, which makes any impact relatively larger and easier to identify. 
From a policy standpoint, if Mondello and Rishe’s claims of significant economic impact from small sporting events hold up under ex post scrutiny, their results send a clear message to metropolitan areas using sports infrastructure as an economic development tool. More modest development plans based upon the economic impact of a large number of smaller events are much more likely to yield positive net benefits than grandiose schemes based on attracting a handful of large mega-events. 


\section{REFERENCES}

Baade, R., and Matheson, V. (2000a). High Octane? Grading the economic impact of the Daytona 500. Marquette Sports Law Journal, 10, 401-415.

Baade, R., and Matheson, V. (2000b). An assessment of the economic impact of the American Football Championship, the Super Bowl, on host communities. Reflets et Perspectives, 39(2-3), 35B46.

Baade, R., and Matheson, V. (2001). Home Run or Wild Pitch? The Economic Impact of Major League Baseball’s All-Star Game. Journal of Sports Economics, 2(4), 307-326.

Baade, R., and Matheson, V. (2004a). The Quest for the Cup: Assessing the Impact of the World Cup. Regional Studies, 38(4), 343-354.

Baade, R., and Matheson, V. (2004b). An Economic Slam Dunk or March Madness? Assessing the Economic Impact of the NCAA Basketball Tournament. Economics of College Sports, John Fizel and Rodney Fort, eds. Westport, CT: Praeger Publishers, 111-133.

Coates, D., and Humphreys, B. (2002). The economic impact of post-season play in professional sports. Journal of Sports Economics, 3(3), 291B99.

Kasimati, E. (2003). Economic aspects and the Summer Olympics: a review of related research. International Journal of Tourism Research, 5, 433-444.

Matheson, V. (2004). Economics Multipliers and Mega-Event Analysis, College of the Holy Cross Working Paper 04-04.

Mondello, M., and Rishe, P., (2004). Comparative Economic Impact Analyses: Differences Across Cities, Events, and Demographics. Economic Development Quarterly, 18(4), 331342. 
Porter, P. (1999). Mega-Sports Events as Municipal Investments: A Critique of Impact

Analysis. in Fizel, John, Elizabeth Gustafson, and Larry Hadley, Sports Economics:

Current Research, Westport, CT: Praeger Press.

Rosentraub, M. (2000). The Economic Value of the Indianapolis Motor Speedway to central Indiana. Report to the Indianapolis Motor Speedway Corporation, Indianapolis, IN. 